\title{
The Interaction of Trichomonas vaginalis and Tritrichomonas foetus with Epithelial Cells in Vitro
}

\author{
Fernando Costa e Silva Filho ${ }^{1,2}$ and Wanderley de Souza* \\ ${ }^{1}$ Laboratório de Microscopia Eletrônica e Ultra-estrutura Celular, Instituto de \\ Biofísica Carlos Chagas Filho, Universidade Federal do Rio de Janeiro, Ilha \\ do Fundão, 21941, Rio de Janeiro and ${ }^{2}$ Departamento de Protozoologia, \\ Instituto Oswaldo Cruz, Pavilhão Carlos Chagas, $3^{\circ}$ andar, Av. Brasil 4365, \\ 21040, Rio de Janeiro, Brasil
}

\begin{abstract}
The Madin-Darby canine kidney epithelial cell line (MDCK) was used as a model for trichomonad-host cell interaction. Two laboratory strains of the human parasite Trichomonas vaginalis and the cattle's parasite Tritrichomonas foetus or their supernatants from axenic cultures were allowed to interact with confluent epithelial cultures. The interaction process studied by transmission and scanning electron microscopy revealed that both parasites adhere to monolayers through flagella, cell body and particularly for $T$. foetus, through the posterior projection of the axostyle. A close contact region between the trichomonad's surface and MDCK cells was observed. A study of the involvement of trichomonad surface component in the interaction process indicated that cytochalasin B treated-parasites adhere much less to epithelial monolayers than untreated parasites. Colchicine treatment did not affect such adhesion. Treatment of the parasites with trypsin reduced the adhesion of trichomonads to monolayers but did not interfere with the cytopathic effect. In contrast, treatment of the parasites with neuraminidase did not interfere with their adhesion to epithelial cells and the monolayer destruction was further increased.
\end{abstract}

Trichomonas vaginalis, the causative agent of human trichomoniasis, and Tritrichomonas foetus, the causal agent of abortion in cattle, are flagellate protozoa which interact with their hosts through the squamous epithelium lining the urogenital cavities $(16,17)$. Many questions related with the pathogenicity mechanisms of these microorganisms remain unanswered. In humans the disease is characterized by severe inflammation and discomfort of the urogenital cavity which has a foul smelling discharge containing numerous free parasites, free epithelial cells or fragments of such tissue with many parasites around them, and polymorphonuclear cells $(11,16)$. Such clinical manifestations observed in symptomatic women are difficult to detect in man $(11,21)$.

Unfortunately, these two diseases have not been properly studied in an experimental animal model which reproduces what is observed in humans and cattle since a good experimental system has yet to be developed despite attempts made with a

\footnotetext{
Abbreviation used: MDCK, Madin-Darby canine kidney cells.

* To whom all correspondence should be addressed.
} 
number of animal species $(16,17)$. On the other hand, simple systems that permit the study of trichomonad-host interaction relationship, have attracted the attention of investigators which have characterized the cytopathic features of either $T$. vaginalis or $T$. foetus in tissue culture. Such studies were made with chicken embryo explants $(1,10)$, HeLa $(3,8,12), \operatorname{HEp}-2(3), \operatorname{McCoy}(3,20)$, Vero (1), RK-13 (14), CHO (23), WISH (19), baboon testis (1), and an otherwise unspecified monkey kidney (24) and baby hamster kidney (12) cell cultures. Recently human vaginal epithelial cells were used for similar purposes (33). However, in vitro these cell lines do not exhibit a behaviour similar to that observed in a true epithelium.

An epithelial cell line useful for studies on the parasite-cell interaction, such as those reported for Entamoeba histolytica (28) and Giardia lamblia (7), is the Madin-Darby canine kidney cell line (MDCK), whose electrical properties (5), morphology (29), metabolic aspects $(6,18)$ and general behaviour on culture vessels (26), are well characterized.

The objective of this study was to analyse the basic aspects of the interaction of $T$. vaginalis and $T$. foetus with confluent MDCK cultures. Our observations show that trichomonads may exert their cytopathic effects either through close contact between the parasites and the epithelium surface or by release of yet unidentified substances from the parasites.

\section{MATERIALS AND METHODS}

Parasites. The Jt strain of Trichomonas vaginalis and the $\mathrm{K}$ strain of Tritrichomonas foetus were used in all experiments. These two strains were characterized in a previous paper (36). They were cultivated in TYM medium (9) or 199 medium supplemented with $10 \%$ bovine serum, at $37^{\circ} \mathrm{C}$ in a humidified atmosphere of $5 \% \mathrm{CO}_{2}$. Parasites taken from the mid $\log$ phase of growth, whose viabilities were always higher than $90 \%$, as checked using erythrosin B (32). They were centrifuged at $1,500 \mathrm{rpm}$ for $15 \mathrm{~min}$, washed twice in $0.01 \mathrm{M}$ phosphate buffer plus $0.9 \% \mathrm{NaCl}$ (PBS) solution at pH 7.2, counted using a Neubauer chamber and resuspended at various concentrations in 199 medium without serum, whose $\mathrm{pH}$ were varied from 5.5 to 8.0.

Epithelial cultures. The MDCK cells were seeded into plastic bottles, in 199 medium plus $10 \%$ bovine serum. The culture vessels were incubated at $37^{\circ} \mathrm{C}$ in an atmosphere of $5 \% \mathrm{CO}_{2}$ for 5 or 7 days. Seven day old cultures were totally confluent. They were carefully washed with PBS and incubated with fresh culture medium or with medium containing parasite suspensions. At regular intervals $(60 \mathrm{~min})$ culture vessels containing MDCK cells alone or with parasites were washed twice with PBS. Some of the cultures were fixed for $30 \mathrm{~min}$ at room temperature in a $2.5 \%$ glutaraldehyde solution made in PBS, and processed for electron microscopy.

Counting cells and parasites. Culture vessels containing epithelial cells and parasites were observed and counted in an inverted microscope at 202.5 X magnification. An ocular lens with small graticules of $256 \mu \mathrm{m}^{2}$ (Carl Zeiss, eyepiece $\mathrm{Kpl} 12.5 \mathrm{X}$ ) was used to estimate the number of epithelial cells adhering to the substrate in each microscopical field, as well as the number of parasites adhered per individual epithelial cell, by counting the numbers for 36 graticules (total area of $9.12 \mathrm{~mm}^{2}$ ). Six microscopical fields were counted in each set, and the data shown represent the mean value of three individual countings.

Treatments with colchicine and cytochalasin B. Both colchicine and cytochalasin B were purchased from Sigma Chem. Co. (USA). A stock solution of colchicine $(1 \mathrm{mg} / \mathrm{ml})$ was prepared in PBS, pH 7.2. Cytochalasin B was dissolved in dimethylsulfoxide (DMSO) to final 
concentrations of $0.1 \mathrm{mg} / \mathrm{ml}$ and $1.0 \%$, respectively. The parasites were washed in PBS and incubated in the presence of concentrations of colchicine and cytochalasin B which inhibited their growth by about 50\% (35). After incubation they were carefully washed with PBS at $10^{\circ} \mathrm{C}$ and inoculated into culture vessels containing confluent epithelial cells.

Enzymatic treatments. Parasites were collected by centrifugation, washed twice in PBS and incubated for $5 \mathrm{~min}$ at room temperature in the presence of $500 \mu \mathrm{g} / \mathrm{ml}$ trypsin (Sigma, type III), $\mathrm{pH} 7.2$, or for $30 \mathrm{~min}$ at $37^{\circ} \mathrm{C}$ in the presence of $0.1 \mathrm{U} / \mathrm{ml}$ neuraminidase from Vibrio cholerae (Calbiochemical). In the latter treatment, the enzyme was dissolved in PBS, pH 6.0, containing $4 \mathrm{mM} \mathrm{CaCl}_{2}$. After incubation, the parasites were washed in PBS and allowed to interact with the epithelial cells.

Protease inhibitors. In some experiments the interaction medium was supplemented with the following protease inhibitors: $2 \mathrm{mM}$ phenylmethylsulphonyl fluoride (PMSF) (BDH Laboratory Chemical Division, England) $10 \mu \mathrm{M}$ pepstatin (Protein Research Foundation, Japan), and $1 \mathrm{mM}$ iodoacetic acid (Sigma Chemical Company, USA.).

Light microscopy. Epithelial cells were seeded on glass coverslips for 7 days under the conditions previously described. They were fixed for $30 \mathrm{~min}$ in a $2.5 \%$ glutaraldehyde solution made in PBS, pH 7.2. The glass coverslips were washed twice with PBS and mounted in a medium containing glycerol: PBS (9:1). Examination of the monolayers was made with a Carl Zeiss photomicroscope with Nomarski contrast.

Transmission electron microscopy. Both parasites and cells were fixed for $30 \mathrm{~min}$ in a solution containing $2.5 \%$ glutaraldehyde in $0.1 \mathrm{M}$ phosphate buffer, $\mathrm{pH}$ 7.0. After fixation they were washed in PBS, postfixed for $15 \mathrm{~min}$ in $1 \% \mathrm{OsO}_{4}$ in phosphate buffer, dehydrated in acetone and embedded in Epon. Ultra-thin sections, stained with uranyl acetate and lead citrate, were examined in a JEOL $100 \mathrm{CX}$ electron microscope at $80 \mathrm{KV}$.

Scanning electron microscopy. Fixed cells and parasites were allowed to adhere to the surface of glass coverslips previously coated for $15 \mathrm{~min}$ with $0.1 \%$ poly-L-lysine (Sigma, MW 30,000-70,000), washed in PBS, and postfixed in $1 \% \mathrm{OsO}_{4}$ in phosphate buffer, for $10 \mathrm{~min}$. Subsequently, they were dehydrated in ethanol and critical point dried with $\mathrm{CO}_{2}$. A $20 \mathrm{~nm}$ thick layer of gold was deposited on the preparations, which were examined with a JEOL 25 SII scanning electron microscope at $15 \mathrm{KV}$. Electronmicrographs were taken using inclination angles of $0^{\circ}, 35^{\circ}$ and $45^{\circ}$.

\section{RESULTS}

The epithelial model. The MDCK cell line exhibits a structural polarization of the plasma membrane into apical and basolateral surfaces, indicating the retention of its differentiated state. Some dome formations, usually observed in lining epithelia in vivo (26), were observed in confluent cultures (Fig. 1). Thin sections of the cells revealed the presence of junctional complexes and many microvilli on the apical surface (Fig. 2).

Parasite-epithelium interaction. Interaction carried out at $4^{\circ} \mathrm{C}$, or with parasites previously fixed with glutaraldehyde, did not result in the destruction of the epithelial monolayers (data not shown). We analysed the interaction process from 1 day until 5 days, at $37^{\circ} \mathrm{C}$, using different parasite: cell $(\mathrm{P} / \mathrm{C})$ ratios. The $\mathrm{P} / \mathrm{C}$ ratio of 5 was used in most of the experiments since ratios lower than 5 did not induce a complete monolayer destruction until 5 days of interaction.

It was observed that the process of epithelium destruction starts $1 \mathrm{~h}$ after the initial contact of both $T$. vaginalis and $T$. foetus with the cells. The first stage of interaction was characterized by a strong adhesion of the parasites to the monolayer 

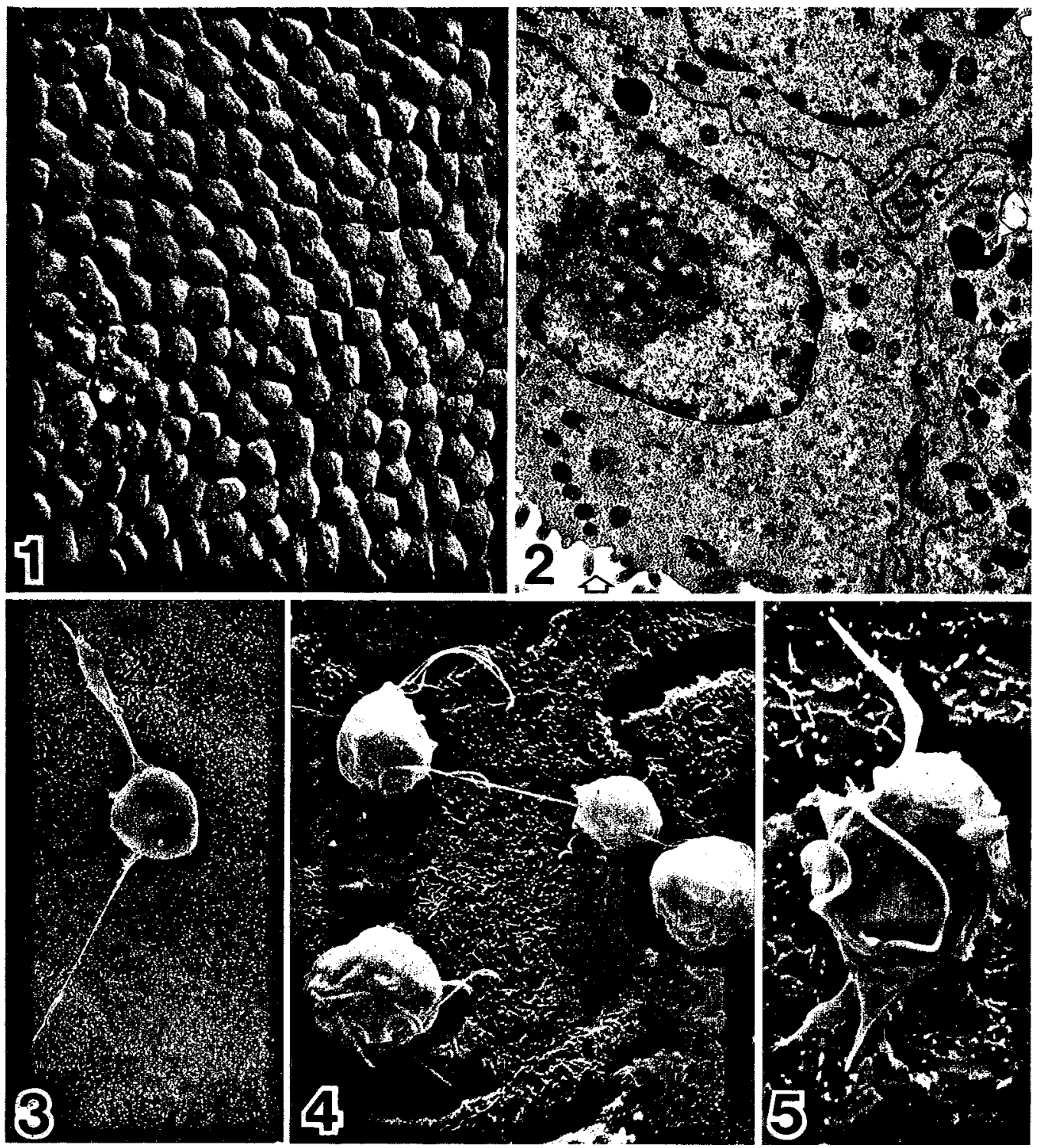

Fig. 1. A seven day old MDCK culture as observed by Nomarski interferential contrast. $\quad \times 980$

Fig. 2. Transmission electron micrograph of MDCK cells showing the presence of microvillion their apical surfaces. $\times 10,660$

Fig. 3. A Trichomonas vaginalis adhering on epithelial monolayer, as revealed by scanning electron microscopy. Cytoplasmic projections of the parasite can be observed (arrows). $\quad \times 1,640$

Fig. 4. Scanning electron micrograph showing a general view of Tritrichomonas foetus to MDCK cells. $\times 2,460$

Fig. 5. Tritrichomonas foetus adhering on epithelial monolayer, as revealed by scanning electron microscopy. Arrow indicates a contact formed between the epithelial surface and the posterior projection of the axostyle. $\times 3,690$ 
TABLE 1. KINETICS OF INTERACTION BETWEEN TRICHOMONADS AND MDCK CELLS (TRICHOMONADS/MDCK RATIO $=5: 1$ )

\begin{tabular}{|c|c|c|c|}
\hline Trichomonads & $\begin{array}{l}\text { Days of } \\
\text { interaction at } 37^{\circ} \mathrm{C}\end{array}$ & $\begin{array}{c}\text { Number of adhering } \\
\text { parasites } / \mathrm{mm}^{2} \text { of monolayer }\end{array}$ & $\begin{array}{c}\text { Number of adhering } \\
\text { MDCK cells }{ }^{* *} \text { per } 9.2 \mathrm{~mm}^{2}(\%)\end{array}$ \\
\hline \multirow[t]{5}{*}{$T$. vaginalis } & 1 & $36.2 \pm 8.4$ & $67.4 \pm 10.6$ \\
\hline & 2 & $43.6 \pm 11.0$ & $60.1 \pm 8.7$ \\
\hline & 3 & $45.2 \pm 8.6$ & $38.2 \pm 11.2$ \\
\hline & 4 & $46.4 \pm 23.5$ & $18.4 \pm 10.0$ \\
\hline & 5 & $43.9 \pm 29.3$ & $16.3 \pm 5.7$ \\
\hline \multirow[t]{5}{*}{$T$. foetus } & 1 & $13.6 \pm 6.2$ & $72.6 \pm 11.8$ \\
\hline & 2 & $18.2 \pm 5.0$ & $63.4 \pm 10.5$ \\
\hline & 3 & $24.3 \pm 4.6$ & $33.7 \pm 9.6$ \\
\hline & 4 & $29.7 \pm 11.8$ & $17.4 \pm 5.8$ \\
\hline & 5 & $28.9 \pm 16.3$ & $18.2 \pm 7.4$ \\
\hline
\end{tabular}

* Interaction experiments were carried out in a humidified atmosphere of $5 \% \mathrm{CO}_{2}$.

** The mean value of $121.4 \mathrm{MDCK}$ cells $/ 9.2 \mathrm{~mm}^{2}$ was considered as $100 \%$.

surface. In the case of $T$. vaginalis the adhesion occurred mainly through its anterior flagella or through the cell body (Fig. 3). In the case of $T$. foetus, however, the adhesion involved mainly the posterior projection of the axostyle (Fig. 4-5), although adhesion mediated by the anterior flagella was also observed.

After 1 day of interaction many epithelial cells or whole fragments of the monolayers became detached from the substrate. In both cases highly motile parasites were found clustering around epithelial cells. Table 1 shows the effect of the time of interaction of $T$. vaginalis and $T$. foetus with epithelial cells on the

TABLE 2. INTERACTION OF EITHER COLCHICINE OR CYTOCHALASIN B-TREATED TRICHOMONADS WITH MDCK CELLS

\begin{tabular}{cccc}
\hline \multirow{2}{*}{ Trichomonads } & $\begin{array}{c}\text { Treatment at } \\
\text { non-proliferative } \\
\text { conditions }\end{array}$ & \multicolumn{2}{c}{ Adhesion $(\%)^{* *}$ on $9.2 \mathrm{~mm}^{2}$} \\
\cline { 2 - 4 }$T$. vaginalis & Control & Trichomonads on epithelia & Epithelia on platic \\
& PBS & $101.3 \pm 9.6$ & $63.7 \pm 10.4$ \\
& Colchicine & $98.6 \pm 10.5$ & $60.5 \pm 9.2$ \\
Cytochalasin B & $86.9 \pm 13.7$ & $58.3 \pm 11.3$ \\
DMSO & $47.8 \pm 13.7$ & $97.4 \pm 12.1$ \\
& Coetus & $76.4 \pm 12.5$ & $78.6 \pm 9.3$ \\
& PBS & & $68.4 \pm 9.8$ \\
& Colchicine & $94.6 \pm 13.6$ & $56.5 \pm 10.0$ \\
& Cytochalasin B & $101.0 \pm 15.3$ & $72.3 \pm 8.5$ \\
DMSO & $54.6 \pm 10.0$ & $101.0 \pm 10.6$ \\
& DMSOl & $81.3 \pm 14.6$ & $83.2 \pm 9.8$
\end{tabular}

* They were carried out at $37^{\circ} \mathrm{C}$ for $60 \mathrm{~min}$ (Colchicine $=10 \mu \mathrm{g} \cdot \mathrm{ml}^{-1}$; Cytochalasin $\mathrm{B}=1 \mu \mathrm{g} \cdot \mathrm{ml}^{-1}$ and $\mathrm{DMSO}=1 \%$ ).

** Adhesion rates were determined after 1 day of interaction. The following mean values were considered as control (100\%): 82.6 for MDCK cells (epithelia on plastic) and 37.4 or 12.9 for $T$. vaginalis or $T$. foetus (trichomonads on epithelia). 
number of cells which remained adhered to the substrate and the number of parasites which adhered to the monolayer. The data show that both $T$. vaginalis and $T$. foetus induced detachment of epithelial cells from the substrate to a similar extent. However, $T$. vaginalis adhered more to the epithelial cells than did $T$. foetus.

The cells which detached from the substrate during interaction for 4 days with parasites were collected and analyzed by transmission electron microscopy. Parasites attached to the surface of these cells showed no unusual morphological changes. In other cases the epithelial cells showed a degenerative aspect as can be seen by its electrolucent cytoplasm (Fig. 7). In these cases a close contact between parasite and the epithelial cell was observed (Figs. 6 and 7).

In order to examine the involvement of surface and cytoskeletal components of the parasites on the process of interaction, we used drugs that interfere with the cytoskeleton components of the parasite. The data shown in Table 2 indicate that incubation of the parasites in the presence of colchicine did not interfere significantly with their adhesion to the epithelial cells or with the effect of the parasites in the release of the cells from the substrate. In contrast, incubation of the parasites in the presence of cytochalasin B significantly decreased the number of parasites attached to the monolayer and protected the monolayer. Dimethylsulfoxide, at the concentration found in the solution of cytochalasin B, did not interfere with the attachment of the parasites to the epithelial monolayers. Incubation of the parasites in the presence of trypsin significantly inhibited their adhesion to the surface of epithelial cells but did not reduce the cytopathic effect of the parasites on the monolayer. In contrast, treatment of the parasites with neuraminidase did not interfere with their
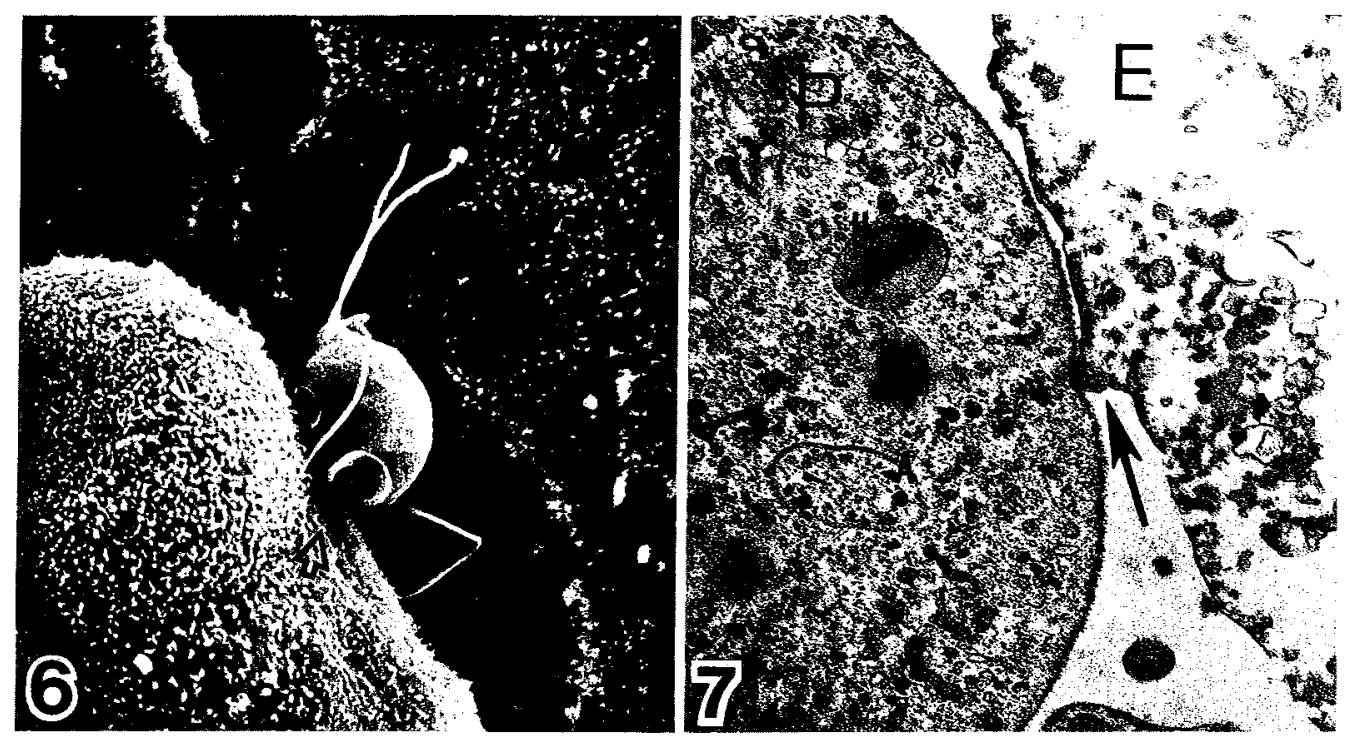

Fig. 6. Scanning electron micrograph showing a close contact (arrow) established between the surfaces of T. vaginalis and the epithelial cell. $\times 2,460$

Fig. 7. Transmission electron microscopy of the adhesion of $T$. vaginalis (P) to a MDCK cell. Damage of the epithelial cell $(\mathrm{E})$ and the presence of a specialized region of contact between the two surfaces (arrow) can be observed; $A=$ axostyle; $H=$ hydrogenosome. $\quad \times 18,650$ 
TABLE 3. INTERACTION OF EITHER TRYPSIN OR NEURAMINIDASE-TREATED TRICHOMONADS WITH MDCK CELLS

\begin{tabular}{lcccc}
\hline \multirow{2}{*}{ Trichomonads } & Trypsin* & Neuraminidase & & \multicolumn{2}{c}{ Adhesion (\%) on $9.2 \mathrm{~mm}^{2 * * *}$} \\
\cline { 4 - 5 }$T$. vaginalis & - & - & Trichomonads on epithelia & Epithelia on plastic \\
\hline & + & - & $102.6 \pm 10.4$ & $70.3 \pm 10.4$ \\
$T$. foetus & - & + & $57.1 \pm 13.2$ & $60.8 \pm 13.6$ \\
& - & - & $109.3 \pm 14.1$ & $36.9 \pm 16.7$ \\
& + & - & $93.2 \pm 11.2$ & $68.6 \pm 7.2$ \\
& - & + & $42.4 \pm 15.8$ & $57.5 \pm 13.4$ \\
& & & $100.9 \pm 13.3$ & $19.9 \pm 10.3$ \\
\hline
\end{tabular}

* Trypsin $\left(500 \mu \mathrm{g} \cdot \mathrm{ml}^{-1}-\right.$ Sigma, Type III) treatment was carried out for $5 \mathrm{~min}$ at $37^{\circ} \mathrm{C}$, in PBS at pH 7.2

** Neuraminidase $\left(0.1 \mathrm{U} \cdot \mathrm{ml}^{-1}-V\right.$. cholerae-Calbiochem) treatment was carried out for $60 \mathrm{~min}$ at $37^{\circ} \mathrm{C}$, in PBS plus $4 \mathrm{mM} \mathrm{CaCl}{ }_{2}$ at $\mathrm{pH} 6.0$.

*** Adhesion rates were determined after $120 \mathrm{~min}$ of interaction. The following mean values were considered as controls (100\%): 26.8 for MDCK cells (epithelia on plastic), 6.2 for $T$. vaginalis and 3.4 for $T$. foetus. Results are expressed as the mean of six independent experiments.

adhesion to the cells but significantly potentiates their cytopathic effect on the monolayers. This effect was more pronounced with $T$. foetus than with $T$. vaginalis (Table 3).

TABLE 4. INTERACTION OF TRIChOMONAS VAginalis OR TRITRICHOMONAS FOETUS With CONFLUENT EPITHELIAL CULTURES WHOSE MEDIUM OF INTERACTION WAS SUPPLEMENTED OR NOT WITH PROTEASE INHIBITORS

\begin{tabular}{lccc}
\hline Addition to confluent MDCK cultures* & $\begin{array}{c} \pm \text { Protease } \\
\text { inhibitors* }\end{array}$ & $\begin{array}{c}\text { MDCK cells } \\
\text { per } 9.2 \mathrm{~mm}^{2}\end{array}$ & $\begin{array}{c}\text { **Variation (\%) } \\
\text { in the number } \\
\text { number of adherent } \\
\text { MDCK cells }\end{array}$ \\
\hline 199 medium plus $10 \%$ bovine serum & - & 119.2 & - \\
199 medium plus $10 \%$ bovine serum & + & 122.6 & +2.85 \\
Supernatant from 7 days old MDCK cells & - & 117.9 & -1.09 \\
Supernatant from 7 days old MDCK cells & + & 120.6 & +1.17 \\
Whole $T$. vaginalis & - & 63.7 & -46.56 \\
Whole $T$. vaginalis & + & 92.6 & $-22.31(+45.37)$ \\
Supernatant from $T$. vaginalis culture & - & 70.5 & -40.86 \\
Supernatant from $T$. vaginalis culture & + & 68.6 & $-42.45(-2.69)$ \\
Whole $T$. foetus & - & 68.5 & -42.53 \\
Whole $T$. foetus & + & 79.3 & $-33.47(+15.77)$ \\
Supernatant from $T$. foetus culture & - & 50.9 & -57.30 \\
Supernatant from $T$. foetus culture & + & 72.8 & $-38.93(+43.02)$ \\
\hline
\end{tabular}

* The experimental procedures are described in Materials and Methods

** Values were obtained by using F-test, and converted to percentage through the following formula:

$$
\mathrm{ED}=\frac{\mathrm{Ec}-\mathrm{Et}}{\mathrm{Ec}} \times 100
$$

where "Ec" is the value of controls and "Et" is the value of treated cells. Values between parenthesis represent the percentual variation related to each set of experiments. Values higher than $10 \%$ are significant. 
An investigation of the exclusive dependence of both parasites on epithelial monolayers as a mechanism of cytotoxicity exerted by the former on cell cultures, indicated that factors secreted by parasites, as shown in Table 4 may be involved in the destruction of the MDCK monolayers, since supernatants collected from axenic cultures of $T$. foetus were able to destroy the epithelial monolayers in a manner similar to that observed with whole parasites. In addition, it was observed that the presence of protease inhibitors during the interaction processes partially inhibited the epithelial destruction. It is also important to point out that, at the concentrations used, none of the protease inhibitors were toxic to the cells.

\section{DISCUSSION}

The MDCK monolayer consists of a single sheet of tightly knit cells that form a continuous layer resembling an in vivo epithelial barrier, hence providing a suitable model for the study of the in vitro interaction with parasites, such as those reported herein.

Many cell lines have been used for cell-trichomonad interaction studies $(15,31)$, with the choice of tissue culture being determined by the objectives of the investigation. In the present case we used the well characterized MDCK cell line, which has in vitro properties characteristic of a true epithelium, since it has been shown that this cell line responds to certain hormones in a way similar to that observed with the epithelium lining of the vaginal cavity (34). Therefore, for our present purposes, the MDCK line offers a good model to study the trichomonad-epithelium interaction.

Our observations, made mainly with the scanning electron microscope, show that both $T$. vaginalis and $T$. foetus adhered to MDCK cells through all regions of the parasites; some through their anterior flagella, others by the posterior projection of the axostyle and yet others through the cell body. Previous observations showed that, during short-term incubation periods, four strains of $T$. vaginalis adhered to HeLa cells preferentially through the portion of the body opposite to the undulating membrane and the midway between flagella and axostyle (2). We can not exclude the possibility that this discrepancy could be due to different surface characteristics of the cell lines used or different exposition of surface components of the parasites. Interestingly, it has been shown that $T$. vaginalis can establish with the MDCK cell surface a close region of contact, which may represent the first step of a highly specialized process of host cell lysis by pathogenic strains of trichomonads, similar to that observed for Entamoeba histolytica (38).

Regarding the mechanism of cytotoxicity of trichomonads some authors claim that it is due to a direct contact established between the parasites surface and the target cell surface (22), while others emphasize that it is mediated mainly by excretion products from the parasites (2). The present observations suggest that both processes can occur. We could obtain images, such as that shown in Fig. 7, where it is possible to see a parasite in close contact with a damaged epithelial cell. The observation that previous incubation of the parasites in the presence of cytochalasin $\mathrm{B}$, a drug which interferes with actin filaments, partially inhibits the ability of the parasite to disrupt the cell monolayer, also support the idea that a direct contact between parasite and host cell is important for parasite to exert its cytotoxic effect. This has been confirmed by our findings (see Table 2 ) that cytochalasin B treatment inhibits the adhesion of the parasites to the surface of the epithelial cells. Previous studies have shown that a similar treatment inhibits the adhesion of $T$. vaginalis to 
glass (4) or plastic (37) substrates. On the other hand, treatment of the parasites with trypsin, under conditions which did not interfere with the parasite's viability, inhibited their adhesion to the epithelium surface although it did not interfere significantly with the integrity of the epithelium (see Table 3). This observation, which suggests that another mechanism independent of adhesion of the parasites to the monolayer is also involved in the disruption of the monolayer, is further supported by the data on neuraminidase-treated parasites. Neuraminidase treatment did not interfere with the adhesion of the parasites to the epithelium surface although potentiates the destruction of the monolayers. It is possible that certain proteases $(27,30)$, glycosidases (13) and neuraminidase (25) found in extracts of trichomonads may play a role in the modulation of the process of interaction of trichomonads with epithelial cells. Support for this idea can be found in some experiments which indicate that filtrates of the supernatant of $T$. vaginalis cultures can destroy some cells (31). In addition, we observed that addition of protease inhibitors to the interaction medium decreases epithelial destruction by $T$. foetus by about $40-50 \%$.

In conclusion our present observations support the view that $T$. vaginalis and $T$. foetus exert their pathogenic effects on epithelial cells in culture either by direct contact, involving the adhesion of the parasites to the surface of the cell, or by the release of components whose localization or chemical nature have yet to be determined.

Acknowledgments. This work has been supported by CNPq, FINEP and CEPG-UFRJ. We thank to Dr. Hertha Meyer for the review of the manuscript, Mr. Sebastião Cruz, Mr. Antonio Lisboa and Miss Sandra B. da Rocha for their expert technical assistance.

\section{REFERENCES}

1. Alderete, J.F. and E. Pearlman. Pathogenic Trichomonas vaginalis in epithelial cell cultures. Brit. J. Vener. Dis. 57, 106-117, 1981

2. Alderete, J.F. and G.E. Garza. Specific nature of Trichomonas vaginalis parasitism of host cell surface. Infect. Immun. 50, 701-708, 1985

3. Brasseur, P. and J. SAvel. Evaluation de la virulence des souches de Trichomonas vaginalis par l'etude de l'effect cytopathogène sur culture de cellules. C. R. Soc. Biol. 176, 849-860, 1982

4. Cappuccinelli, P. and L. Varesio. The effect of cytochalasin B, colchicine and vinblastine on the adhesion of Trichomonas vaginalis to glass surfaces. Int. J. Parasitol. 5, 57-61, 1975

5. Cereijido, M. Electrical properties of Madin-Darby canine kidney cells. Fed. Proc. 43, 22302235,1984

6. Cereijido, M., E. Stefani and A. Martinez-Palomo. Occluding junctions in a cultured transporting epithelium: structural and functional heterogeneity. J. Membrane Biol. 53, 19-32, 1980

7. Chavez, B., F. Knaippe, L. Gonzalez-Mariscal and A. Martinez-Palomo. Giardia lambia: electrophysiology and ultrastructure of cytopathology in cultured epithelial cells. Exp. Parasitol. 61, 379-389, 1986

8. Christian, R.T., N.F. Miller, P.P. Ludovici and G.M. Riley. A study of Trichomonas vaginalis in human cell cultrue. Am. J. Obstet. Gynecol. 85, 947-954, 1963

9. Diamond, L.S. The establishment of various trichomonads from animals and man in axenic cultures. J. Parasitol. 43, 488-490, 1957

10. FARris, V.K. and B.M. HonIGBERG. Behaviour and pathogenicity of Trichomonas vaginalis Donné in chick liver cell cultures. J. Parasitol. 56, 849-882, 1970

11. Friedrich Jr, E.G. Vaginitis. Am. Fam. Physician 28, 28-42, 1983

12. Gentry, G.A., N. Lawrence and W. Lushbaugh. Isolation and differentiation of herpes 
simples virus and Trichomonas vaginalis in cell culture. J. Clin. Microbiol. 22, 199-204, 1985

13. Harrap, G.J., W.M. Watkins. Enzymes of Trichomonas foetus. Separation and properties of two $\beta$-galactosidases. Biochem. J. 117, 667-675, 1970

14. Heath, E. Behaviour and pathogenicity of Trichomonas vaginalis in epithelial cell cultures. Brit. J. Vener. Dis. 57, 106-117, 1981

15. Hogue, M.J. The effect of Trichomonas vaginalis on tissue cultured cells. Am. J. Hyg. 37, 142152,1943

16. Honigberg, B.M. Trichomonads of importance in human medicine. In: Parasitic Protozoa. Ed. Kreier, J.P. Vol. 2. New York; Academic Press, pp. 275-454, 1978a

17. Honigberg, B.M. Trichomonads of veterinary importance. In: Parasitic protozoa. Ed. Kreier, J.P. Vol. 2. New York; Academic Press, pp. 164-273, 1978b

18. Kennedy, B.G. and J.E. LeVer. Regulation of $\mathrm{Na}^{+}, \mathrm{K}^{+}$-ATPase activity in MDCK kidney epithelial cell cultures: role of growth phase, cyclic AMP and chemical inducers of dome formation and differentiation. J. Cell Physiol. 121, 51-63, 1984

19. KorbeCKI, M. and E. DyNer. Application of WISH cell cultures to produce large populations of vaginal trichomonads. Bull. Acad. Pol. Sci. Ser. Sci. Bio. 24, 259-261, 1976

20. Kotcher, E. and A.C. Hoogasin. Cultivation of Trichomonas vaginalis Donné, 1837, in association with tissue cultures. J. Parasitol. (suppl.) 43, 39, 1957

21. KRIEGER, J.N. Urologic aspects of trichomoniasis. Invest. Urol. 18, 411-417, 1981

22. KRIEger, J.N., J.I. RAVDIN and M.F. ReIN. Contact-dependent cytopathogenic mechanism of Trichomonas vaginalis. Infect. Immun. 50, 778-786, 1985

23. Krieger, J.N., M.A. PoIsson and M.F. ReIN. Beta-hemolytic activity of Trichomonas vaginalis correlates with virulence. Infect. Immun. 41, 1291-1295, 1983

24. Kulda, J. Effect of different species of trichomonads on monkey kidney cell cultures. Folia Parasitol. 14, 295-310, 1967

25. Kulda, J. and H. Závadová. Neuraminidase in Tritrichomonas foetus and T. suis. J. Protozool. 22, 65A-66A, 1975

26. Lever, J.E. Regulation of dome formation in kidney epithelial cell cultures. Ann. N. Y. Acad. Sci. 372, 371-383, 1981

27. Lockwood, B.C., M.J. NoRTH and G.H. Coombs. Trichomonas vaginalis Tritrichomonas foetus and Trichomitus batrachorum: comparative proteolytic activity. Exp. Parasitol. 58, 245-253, 1984

28. Martinez-Palomo, A., A. Gonzalez-Robles, B. Chavez, E. Orozco, S. Fernandez-Castelo and A. Cervantes. Structural basis of the cytotoxity mechanisms of Entamoeba histolytica. $J$. protozool. 32, 166-175, 1985

29. Meza, I., G. Ibara, M. Sabanero, A. Martinez-Palomo and M. Cereijido. Occluding junctions and cytoskeletal components in a cultured transporting epithelium. J. Cell Biol. 87, $746-754,1980$

30. NoRth, M.J. Comparative biochemistry of the proteinases of eukaryotic microorganisms. Microbiol. Rev. 46, 308-340, 1982

31. Pindak, F.F., W.A. Gardner Jr. and M.M. de PindaK. Growth and cytopathogenicity of Trichomonas vaginalis in tissue cultures. J. Clin. Microbiol. 23, 672-678, 1986

32. Phillips, H.P. and J.E. Terryberry. Counting actively metabolizing tissue cultured cells. Exp. Cell Res. 13, 341-347, 1957

33. Rasmussen, S.F., M.H. Nielsen, I. Lind and J.M. Rhodes. Morphological studies of the cytotoxicity of Trichomonas vaginalis to normal human vaginal epithelial cells in vitro. Genitour. Med. 62, 240-246, 1986

34. Rindler, M.J., L.M. Chuman, L. Shaffer and M.H. SaIER. Retention of differentiated properties in an established dog kidney cell line (MDCK). J. Cell Biol. 81, 635-648, 1979

35. Silva Filho, F.C. and W. de Souza. Effect of colchicine, vinblastine and cytochalasin B on cell surface anionic sites of Tritrichomonas foetus. J. Protozool. 33, 6-10, 1986

36. Silva Filho, F.C., C.A. Elias and W. de Souza. Further studies on the surface charge of various strains of Trichomonas vaginalis and Tritrichomonas foetus. Cell Biophys. 8, 161-176, 1986

37. Silva Filho, F.C., C.A. Elias and W. de Souza. Role of divalent cations, pH, cytoskeleton components and surface charge on the adhesion of Trichomonas vaginalis to a polystyrene substrate. Mem. Inst. Oswaldo Cruz, 82, 379-384, 1987

38. Young, J.D.-E., T.M. Young, L.P. Lu, J.C. Unkeless and Z.A. CoHN. Characterization of a membrane-pore forming protein from Entamoeba histolytica. J. Exp. Med. 156, 1677-1690, 1982 